\title{
Anti-inflammatory/anti-amyloidogenic effects of plasmalogens in lipopolysaccharide-induced neuroinflammation in adult mice
}

\author{
Masataka Ifuku', Toshihiko Katafuchi ${ }^{*}$, Shiro Mawatari ${ }^{2}$, Mami Noda ${ }^{3}$, Kiyotaka Miake ${ }^{4}$, Masaaki Sugiyama ${ }^{4}$ \\ and Takehiko Fujino ${ }^{2}$
}

\begin{abstract}
Background: Neuroinflammation involves the activation of glial cells in neurodegenerative diseases such as Alzheimer's disease (AD). Plasmalogens (PIs) are glycerophospholipids constituting cellular membranes and play significant roles in membrane fluidity and cellular processes such as vesicular fusion and signal transduction.

Methods: In this study the preventive effects of Pls on systemic lipopolysaccharide (LPS)-induced neuroinflammation were investigated using immunohistochemistry, real-time PCR methods and analysis of brain glycerophospholipid levels in adult mice.

Results: Intraperitoneal (i.p.) injections of LPS $(250 \mu \mathrm{g} / \mathrm{kg})$ for seven days resulted in increases in the number of Iba-1-positive microglia and glial fibrillary acidic protein (GFAP)-positive astrocytes in the prefrontal cortex (PFC) and hippocampus accompanied by the enhanced expression of IL-1 $\beta$ and TNF-a mRNAs. In addition, $\beta$-amyloid $\left(A \beta_{3-16}\right)$-positive neurons appeared in the PFC and hippocampus of LPS-injected animals. The co-administration of PIs (i.p., $20 \mathrm{mg} / \mathrm{kg}$ ) after daily LPS injections significantly attenuated both the activation of glial cells and the accumulation of A $\beta$ proteins. Finally, the amount of PIs in the PFC and hippocampus decreased following the LPS injections and this reduction was suppressed by co-treatment with PIs.
\end{abstract}

Conclusions: These findings suggest that Pls have anti-neuroinflammatory and anti-amyloidogenic effects, thereby indicating the preventive or therapeutic application of Pls against AD.

Keywords: Neuroinflammation, Phospholipids, Microglia, Alzheimer's disease

\section{Background}

It has been demonstrated in mice and rats that the systemic administration of lipopolysaccharide (LPS) and polyriboinosinic:polyribocytidylic acid (poly I:C), ligands for toll-like receptor (TLR) 4 and TLR 3, respectively, induce neuroinflammation in the central nervous system (CNS), thus leading to neurodegeneration, the suppression of neurogenesis and the impairment of cognitive behavior [1-3]. One of the possible mechanisms of neuroinflammation may be the production of $\beta$-amyloid proteins $(A \beta)$. For example, a single intraperitoneal (i.p.) injection of LPS increases the activity of $\beta$-secretase, a

\footnotetext{
* Correspondence: kataf@physiol.med.kyushu-u.ac.jp

'Department of Integrative Physiology, Graduate School of Medical Sciences, Kyushu University, Fukuoka 812-8582, Japan

Full list of author information is available at the end of the article
}

key rate-limiting enzyme that initiates $A \beta$ formation, and the concentration of brain $A \beta_{1-42}$ in adult but not young mice [1]. Furthermore, the intracellular accumulation of $A \beta_{1-42}$ in hippocampal pyramidal neurons following daily injections of LPS for seven days has been immunohistochemically demonstrated [1]. Although the precise mechanisms underlying LPS-induced amyloidogenesis have not yet been determined, it is likely that proinflammatory cytokines such as IL- $1 \beta$, TNF- $\alpha$, IFN- $\gamma$, and reactive oxygen/nitrogen species (ROS/RNS) released from activated glial cells play significant roles in $\mathrm{A} \beta$ formation, which are suppressed by NSAIDs through the activation of peroxisome proliferator-activated receptor- $\gamma($ PPAR- $\gamma)$ [4-6].

Plasmalogens (Pls) are unique glycerophospholipids that contain a vinyl ether bond at the $s n-1$ position of the 
glycerol moiety. They are found in all mammalian tissues, especially in the heart and brain, in which ethanolamine Pls (PlsEtn) are much more abundant than choline Pls (PlsCho) [7]. Pls release either docosahexaenoic acid (DHA) or arachidonic acid (ARA) from the $s n-2$ position through the activation of Pls-selective phospholipase $\mathrm{A}_{2}$ $\left(\mathrm{Pls}-\mathrm{PLA}_{2}\right)$ [8,9]. Pls are not only structural membrane components and reservoirs for second messengers, but they are also involved in membrane fusion, ion transport and cholesterol efflux [7]. In addition, the vinyl ether bond at the $s n-1$ position makes Pls more susceptible to oxidative stress than corresponding ester bonded glycerophospholipids, which act as antioxidants and protect cells from oxidative stress [10-13].

It has been shown that patients suffering from Alzheimer's disease (AD) have reduced PlsEtn levels in the cortex and hippocampus [14-16]. The reduction of PlsEtn levels seems to be specific since other neurodegenerative diseases such as Huntington's and Parkinson's do not show decreases in corresponding affected brain regions (the caudate nucleus and the substantia nigra, respectively) [7,14,17]. Furthermore, circulating PlsEtn levels are also decreased depending on the severity of dementia $[18,19]$. It has been suggested that deficiencies of PlsEtn may lead to increases in the vulnerability of neural membranes to oxidative stress, destabilization of membranes, impairment of muscarinic cholinergic signals and abnormal amyloid precursor processing $[7,17,20]$.

Although $\mathrm{Pls}$ are considered to be involved in the pathology of $\mathrm{AD}$, the influence of Pls on $\mathrm{A} \beta$ accumulation has not been examined, probably due to the difficulty of extracting massive amounts of intact Pls. Recently, we developed a new method for preparing highly pure Pls [21], which enabled us to investigate this issue. In the present study, in order to elucidate the anti-neuroinflammatory/anti-amyloidogenic actions of Pls, we investigated the effects of co-administered Pls on the systemic LPS-induced changes in the morphology of glial cells, the expression of cytokines, the accumulation of $\mathrm{A} \beta$ and the levels of Pls in the prefrontal cortex (PFC) and hippocampus of adult mice.

\section{Methods}

All experimental procedures involving the use of animals were approved by the Ethics Committee on Animal Experiments at Kyushu University and were in accordance with the Guiding Principles for the Care and Use of Animals of the Physiological Society of Japan. All efforts were made to minimize animal suffering and the number of animals used in the study.

\section{Animals}

Male C57/6J mice weighing 32 to $37 \mathrm{~g}$ (10 months old) were used in all experiments. The animals were housed five per cage at a temperature of $22 \pm 2^{\circ} \mathrm{C}$ with 12 hour light/12 hour dark cycles (lights on at 8:00) with free access to laboratory food and water. The mice were randomly divided into four groups: control (Con), LPS, LPS + Pls and Pls. LPS (Sigma-Aldrich, St. Louis, MO, USA) was dissolved in saline, while the Pls were dissolved in corn oil then sonicated to ensure complete solubilization. The LPS group received an i.p. injection of LPS $(250 \mu \mathrm{g} / \mathrm{kg})$ followed by corn oil in the morning (9:00 to 10:00) daily for seven days (days 1 to 7 ). The LPS + Pls group was treated with LPS followed by Pls (20 $\mathrm{mg} / \mathrm{kg}$ ) for seven days, while the Pls group was injected with saline and Pls. The Con group was given saline and corn oil for seven days. All animals were sacrificed on day 8 . The body weights were measured in the morning before injection on day 1 to day 8 .

\section{PI preparation}

The Pls used in the present study were prepared from chicken breast muscle using a previously reported method [21]. A HPLC used for phospholipid separation [22] indicated that the purified Pls consisted of $47.6 \%$ PlsEtn, 49.3\% PlsCho, 2.4\% sphingomyelin (SM) and $0.5 \%$ other phospholipids. The composition of fatty acids of PlsEtn and PlsCho was analyzed using the previously described HPLC method [21], as shown in Table 1.

\section{Immunohistochemistry and immunofluorescence}

The mice were deeply anesthetized with pentobarbital (50 $\mathrm{mg} / \mathrm{kg}$ ) and transcardially perfused with PBS followed by $4 \%$ paraformaldehyde. For each animal, the brain was removed, post-fixed for 24 hours and then transferred successively to $20 \%$ and $30 \%$ sucrose solutions. Subsequently, the brains were frozen on a cold stage and sliced into $30 \mu \mathrm{m}$ thicknesses using a cryostat. The sections were permeabilized with $0.3 \%$ Triton-X 100 (Sigma-Aldrich) in PBS for 15 minutes and blocked in PBS containing 1\% BSA and 5\% normal donkey serum (Jackson ImmunoResearch Lab., West Grove, PA, USA)

Table 1 The fatty acid composition of the PlsEtn and PlsCho in the purified Pls

\begin{tabular}{llcr}
\hline $\begin{array}{l}\text { Numerical } \\
\text { symbol }\end{array}$ & (palmitic acid) & $\begin{array}{c}\text { PlsEtn } \\
\mathbf{( \% )}\end{array}$ & $\begin{array}{c}\text { PlsCho } \\
\mathbf{( \% )}\end{array}$ \\
\hline $16: 0$ & (stearic acid) & 3.6 & 20.5 \\
$18: 0$ & (oleic acid) & 2.2 & 12.4 \\
$18: 1, n-9$ & (linoleic acid) & 26.3 & 20.1 \\
$18: 2, n-6$ & (a-linolenic acid) & 4.1 & 10.1 \\
$18: 3, n-3$ & (arachidonic acid, ARA) & 7.2 & 3.8 \\
$20: 4, n-6$ & (docosahexaenoic acid, DHA) & 18.6 & 17.2 \\
$22: 6, n-3$ & & 13.2 & 2.3 \\
others & & & 13.6 \\
\hline
\end{tabular}


for 60 minutes at room temperature. The sections were incubated in blocking solution (Block Ace, Dainippon Pharmaceutical, Osaka, Japan) for 30 minutes at room temperature and then incubated with rabbit polyclonal antibodies against Iba-1 (1:10000; Wako Pure Chem. Indus., Osaka, Japan), which are known to have specific affinity for microglial $\mathrm{Ca}^{2+}$-binding proteins and are highly expressed by activated microglia, and anti-glial fibrillary acidic proteins (GFAPs, 1:3000; Sigma-Aldrich) for astrocytes in $10 \%$ Block Ace in PBS at $4{ }^{\circ} \mathrm{C}$ overnight. Other sections were incubated with polyclonal antibodies against $A \beta_{3-16}$ (1:1000; ab14220, Abcam, Cambridge, UK) and NeuN (1:1000; Millipore, Billerica, MA, USA). According to the manufacturer's instructions, ab14220s react with all isoforms of mouse and rat $A \beta$. The rinsed sections were incubated for six hours with Alexa Fluor 488 goat anti-rabbit IgG or Alexa Flour 568 goat anti-mouse immunoglobulin G (IgG) (1:1000; Invitrogen, Eugene, OR, USA) at room temperature. Every treatment was followed by washing three times for five minutes with PBS. The sections were then mounted in the perma fluor aqueous mounting medium (Thermo Fisher Scientific, Waltham. MA, USA).

\section{Quantitative analysis of fluorescence intensity}

All samples were analyzed with a confocal laserscanning microscope (LSM510 Meta; Carl Zeiss, Jena, Germany). The number of glial cells in 90 to 100 areas of $200 \mu \mathrm{m} \times 200 \mu \mathrm{m}$ in four slices per brain was counted and the average number $/ 4 \times 10^{4} \mu \mathrm{m}^{2}$ was obtained for each brain.

\section{Real-time PCR}

Mice were deeply anaesthetized with pentobarbital and perfused transcardially with phosphate buffered saline, then the PFC and hippocampus were removed immediately. Total RNA was isolated from the samples using magnetic beads (MagExtractor system; Toyobo, Tokyo, Japan) after homogenizing the tissues. Primer pairs were chosen to flank at least one intron. The amount of total RNA was quantified by measuring the optical density 250 using a Nanodrop spectrophotometer (Nanodrop, Wilmington, DE, USA). For reverse transcription, 100 ng of total RNA was transferred to the reaction using an RNA PCR kit (AMV) (Takara Bio Inc., Ootsu, Japan) and 9-mer random primers. SYBR-Green real-time PCR (Applied Biosystems, Foster City, CA, USA) was performed on cDNA prepared from each sample using the THUNDERBIRD SYBR qPCR Mix, ROX reference dye (Toyobo) and $0.5 \mathrm{mM}$ of each primer. The data were analyzed using 7500 System software v2.0 (Applied Biosystems). All values of cytokines were normalized to the corresponding $\beta$-actin concentration obtained using the same method. The sequences of primers were follows:
IL-1 $\beta$, sense; $5^{\prime}$ - CTCCATGAGCTTTGTACAAGG - $3^{\prime}$, antisense; $\quad 5^{\prime}-$ TGCTGATGTACCAGTTGGGG $-3^{\prime}$; TNF- $\alpha$, sense; $5^{\prime}$ - CCACCACGCTCTTCTGTCTAC $-3^{\prime}$, antisense; $5^{\prime}$ - TGGGCTACAGGCTTGTCACT $-3^{\prime} \quad \beta-$ actin, sense; $5^{\prime}$ - TTGCTGACAGGATGCAGAAGGAG $-3^{\prime}$, antisense; 5' - GTGGACAGTGAGGCCAGGAT - $3^{\prime}$. The predicted sizes of the PCR products were $245 \mathrm{bp}$ for IL-1 $\beta, 196 \mathrm{bp}$ for TNF- $\alpha$, and $127 \mathrm{bp}$ for $\beta$-actin mRNA.

\section{Measurement of the PI levels in the PFC and hippocampus}

Mice were deeply anesthetized with pentobarbital (50 $\mathrm{mg} / \mathrm{kg}$ ) and transcardially perfused with sterile PBS. For each animal, the brain was removed and the PFC and hippocampus were dissected in a dish filled with icecold PBS. The samples (300 mg to $500 \mathrm{mg}$ ) were stored at $-80^{\circ} \mathrm{C}$ until $\mathrm{Pl}$ measurement. Total lipids were extracted using the method of Folch and coworkers [23], and the relative composition of phospholipid classes, including Pls, was measured as previously reported [22].

\section{Statistical analysis}

The results are expressed as the mean \pm SEM. The body weights (BWs), numbers of Iba- $1^{+}$and $\mathrm{GFAP}^{+}$cells and amounts of mRNAs were compared using one-way analysis of variance (ANOVA) followed by post hoc (Scheffe's) test. Changes in the PlsEtn levels and the ratio of PlsEtn/Phosphatidyl Etn (PEtn) determined after LPS and $\mathrm{Pl}$ injection were evaluated using the nonparametric Kruskal-Wallis test followed by the Steel test for multiple comparisons. Values of $P<0.05$ were considered to be statistically significant.

\section{Results}

\section{Body weight changes after LPS and PIs}

The BWs of the mice in the LPS group started to decrease on day 2 and showed significant differences between groups on day 4 that lasted until day 8 (day 4: $\mathrm{F}(3,28)=7.1$, day $5: \mathrm{F}(3,28)=8.1$, day $6: \mathrm{F}(3,28)=6.0$, day 7: $\mathrm{F}(3,28)=9.0$ and day $8: \mathrm{F}(3,28)=9.4, P<0.01$, respectively, each group, $n=8$ ). The post hoc test indicated that the BWs of the LPS group were different from those of the control (Con) group (day 4, 5, 7 and 8, $P<0.05$ ) and the Pls group (from day 4 to $8, P<0.01$ ). However, the LPS + Pls group showed no significant differences between either the Con or Pls group in terms of BW at any point (Figure 1).

\section{Suppression of glial activation by Pls}

As shown in Figure 2Aa, the Con group that received saline and corn oil for seven days showed typical features of Iba-1-positive (green) resting microglia with small and compact soma bearing ramified processes $\left(a^{\prime}\right)$ in the PFC. GFAP was immunostained with weak fluorescence 


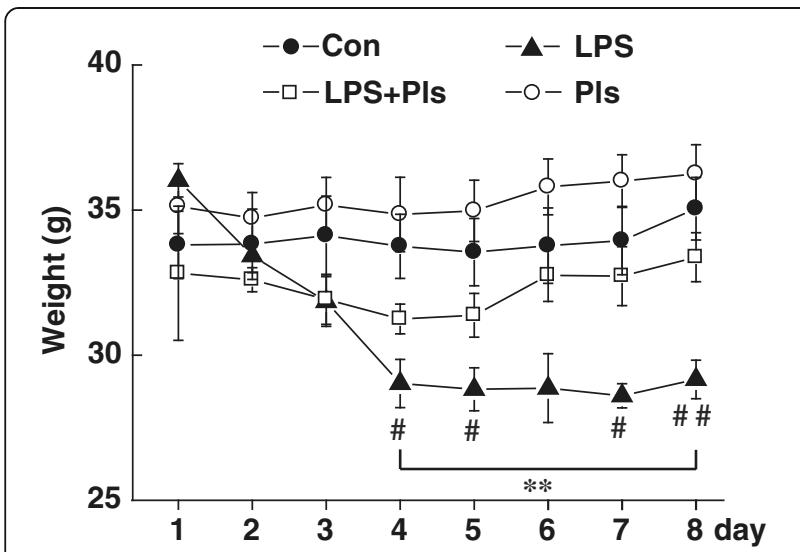

Figure 1 Body weight (BW) changes after LPS/PIs

administration. BW was measured immediately prior to injection on days 1 to 7 and on day 8 before sacrifice. Filled circle: Con group; open circle: Pls group; filled triangle: LPS group; and open rectangle: LPS + Pls group. Each group, $n=8,{ }^{* *}, P<0.1$, LPS versus Pls group; $\#, P<0.05$ and \#\#, $P<0.01$, LPS versus Con group. Con, control; LPS, lipopolysaccharide; Pls, plasmalogens.

(red) in astrocytes (b). However, the i.p. administration of LPS $(250 \mu \mathrm{g} / \mathrm{kg} /$ day) for seven days (LPS group, second row) resulted in neuroinflammation showing increased numbers of Iba-1-positive microglia and intense immunoreactivity (d) with activated phenotypes of marked cellular hypertrophy and retraction of cytoplasmic processes (d'). GFAP-positive astrocytes also increased in number and intensity (e). As shown in Figure $2 \mathrm{Ag}$ and $\mathrm{h}$, the increases in the number of activated microglia and astrocytes in the PFC were suppressed by i.p. administration of LPS and Pls $(20 \mathrm{mg} /$ kg) (LPS + Pls group). Iba-1-positive microglia and GFAP-positive astrocytes did not merge with each other in all groups (c, f, i, and l). Figure $2 \mathrm{~B}$ shows a summary of the LPS-induced increases in the number of glial cells and the suppression of this increase by Pls (each bar, $n=8$ ). The number of microglia (left) and astrocytes (right) significantly increased following LPS injection $(\mathrm{F}(3,28)=38.4, P<0.01 ; \quad \mathrm{F}(3,28)=45.8$, $P<0.01$, respectively). The multiple-range test indicated that the numbers of microglia and astrocytes in the LPS group were different from those in the Con, Pls, and LPS + Pls groups (Scheffe's test, $P<0.01$, respectively), while the LPS + Pls group did not differ from the Con or Pls groups for either microglia or astrocytes.

In the CA1 region of the hippocampus, both Iba-1positive microglia and GFAP-positive astrocytes increased in number in the LPS group (Figure 3Ad and e) compared with that observed in the control group (a and b). Similar to that observed in the PFC, the increases in the number of activated glial cells were attenuated following the administration of Pls ( $g$ and $h$ ). As shown in Figure 3B, the statistical analysis indicated significant differences in the numbers of microglia (left: $F(3,28)=10.7, P<0.01$ ) and astrocytes (right: $\mathrm{F}(3,28)=11.2, \quad P<0.01$ ) between the groups (each bar, $n=8)$. LPS injection increased the numbers of microglia (left: $P<0.01$ ) and astrocytes (right: $P<0.01$ ). The increases were significantly suppressed by Pls to the levels of microglia and astrocytes observed in the Con and Pls groups (LPS + Pls group, $P<0.05$, respectively).

As shown in Figure 4A, the dentate gyrus (DG) of the hippocampus also demonstrated LPS-induced increases in the number and intensity of immunostaining for Iba1 in microglia (d) and GFAP in astrocytes (e) compared with that observed in the Con group ( $a$ and b). These increases were suppressed by simultaneous injection of Pls ( $g$ and $f$, respectively). One-way ANOVA indicated significant differences in the numbers of microglia (Figure 4B, left: $F(3,28)=41.4, P<0.01$ ) and astrocytes (right: $\mathrm{F}(3,28)=11.5, P<0.01)$ between the groups (each bar, $\mathrm{n}=8$ ). The differences in the numbers of microglia and astrocytes in the Con and $\mathrm{Pls}$ groups $(P<0.01)$ and the LPS + Pls group were significant $(P<0.01$ and $P<0.05$, respectively).

\section{Suppression of LPS-induced increases in cytokine mRNA by Pls}

As shown in Figure 5A, the relative amounts of mRNAs for IL-1 $\beta$ (left) and TNF- $\alpha$ (right) in the PFC were significantly different (ANOVA test, $\mathrm{F}(3,16)=19.3, P<0.01$, and $\mathrm{F}(3,16)=14.9, P<0.01$, respectively) between the groups (each bar, $\mathrm{n}=5$ ). The post hoc test indicated that the levels of both IL- $1 \beta$ and TNF- $\alpha$ mRNAs in the LPS group were significantly higher than those observed in the other groups (Scheffe's test, $P<0.01$, respectively), while the levels in the LPS + Pls group were not different from those observed in the Con and Pls groups, suggesting that Pls have a suppressive effect on LPS-induced cytokine expression (Figure 5A).

Similar to the findings observed in the PFC, both cytokine mRNAs increased in the hippocampus in the LPS group (left: IL-1 $\beta, F(3,16)=10.1, P<0.01$; right: TNF- $\alpha$, $\mathrm{F}(3,16)=17.7, P<0.01)$ in comparison to that observed in the other three groups (Figure $5 \mathrm{~B}, P<0.01$, respectively; each bar, $\mathrm{n}=5$ ).

\section{Suppression of LPS-induced $A \beta$ accumulation by PIs}

The presence of LPS-induced amyloidogenesis in the PFC and hippocampus following LPS injection was investigated. As shown in Figure 6, a weak fluorescence for $A \beta_{3-16}$ immunoreactivity (green) in the PFC of the control group (Con, b) was apparently increased in the LPS group (e). The increase in $A \beta_{3-16}$ immunoreactivity was attenuated in the LPS + Pls group (h). Neurons in the cortex were stained with NeuN (red, a, d and g), and most of the $A \beta_{3-16}$ fluorescence merged with the $\mathrm{NeuN}$ 


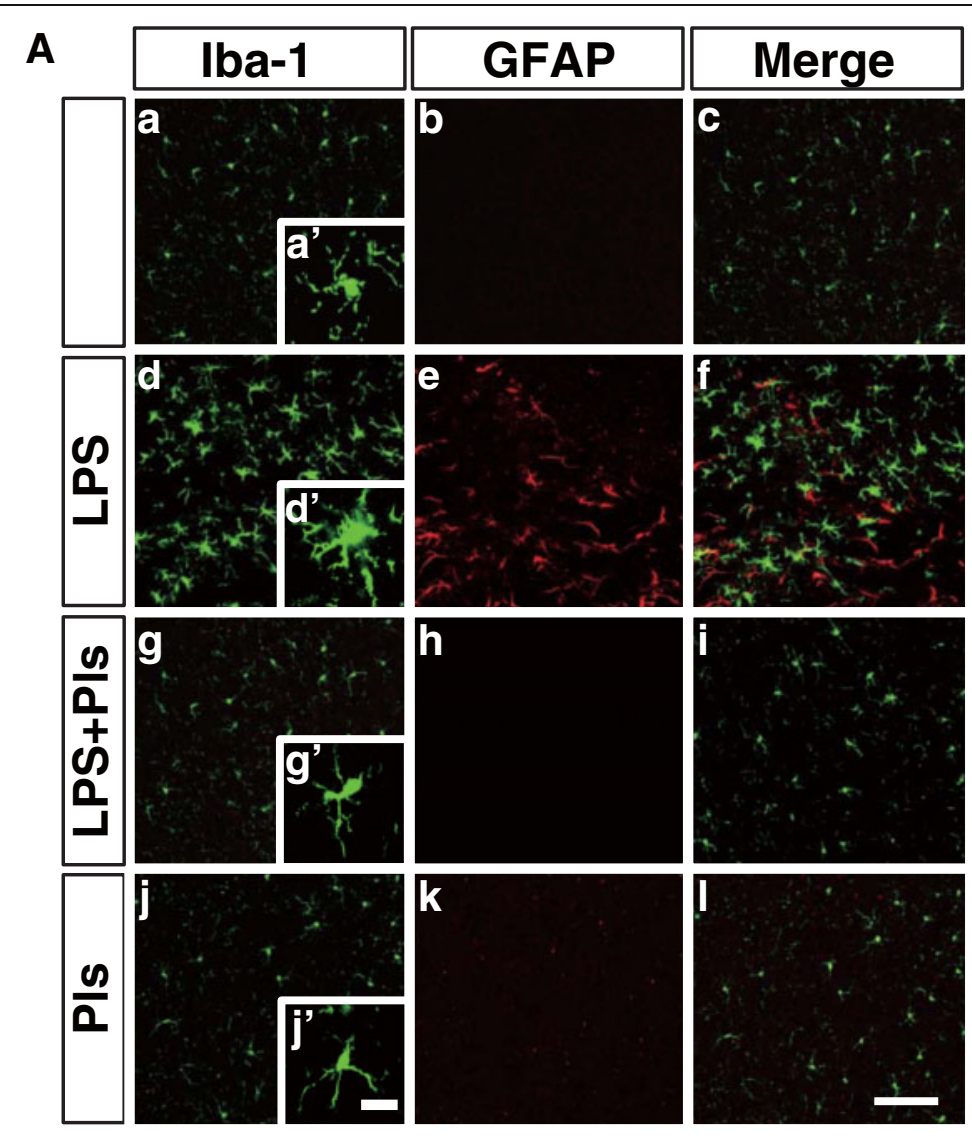

B

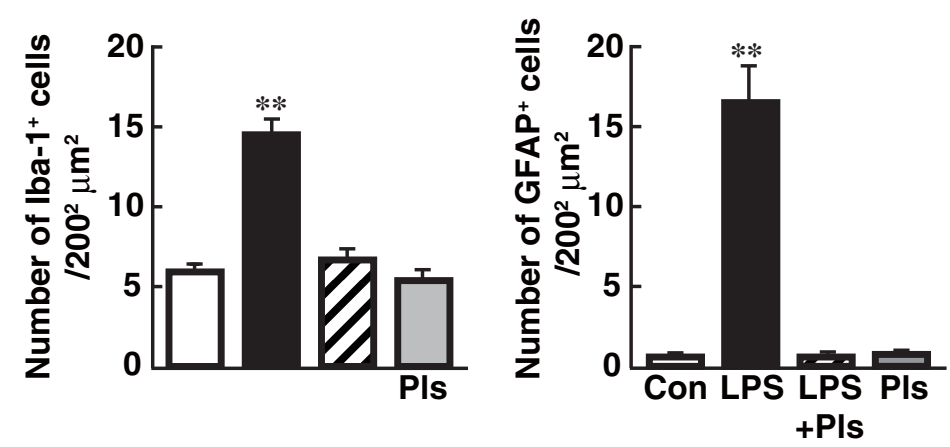

Figure 2 Activation of glial cells in the murine PFC following LPS injection (i.p.) performed on seven consecutive days and suppression by Pls applied immediately after each LPS injection. A, Iba-1-positive microglia (green) and GFAP-positive astrocytes (red). The number and intensity of immunoreactivity of microglia increased after LPS treatment (d) with hypertrophy (d') compared with that observed in the Con group ( $a$ and $a^{\prime}$ ) and was suppressed by application of Pls ( $g$ and $g^{\prime}$ ). The Pls group ( $j$ and $j^{\prime}$ ) showed no differences from the Con group. GFAP-positive astrocytes also demonstrated increases in number and intensity due to LPS and suppression by Pls (middle column). Iba-1 and GFAP immunostaining did not merge with each other (f). Scale bar: low magnification, $100 \mu \mathrm{m}$, and high magnification, $20 \mu \mathrm{m}$. B, A summary of LPS-induced increases in the numbers of microglia (left) and astrocytes (right) and suppression by Pls (each bar, $\mathrm{n}=8$ ). ${ }^{* *}, P<0.01$, respectively. Con, control; GFAP, glial fibrillary acidic protein; LPS, lipopolysaccharide; PFC, prefrontal cortex; PIs, plasmalogens.

immunoreactivity, indicating intracellular localization of $A \beta$ (yellow in $\mathrm{f}$ ).

Accumulations of $A \beta$ were also observed in the CA1 region of the hippocampus in the LPS group (Figure 7, e). Similar to that observed in the PFC, enhanced $A \beta_{3-16}$ immunoreactivity was markedly attenuated by $\mathrm{Pl}$ administration (LPS + Pls group, h). Again, the presence of intracellular accumulation of $A \beta$ in the pyramidal neurons was detected using double staining for $A \beta_{3-16}$ and NeuN (f and i). 

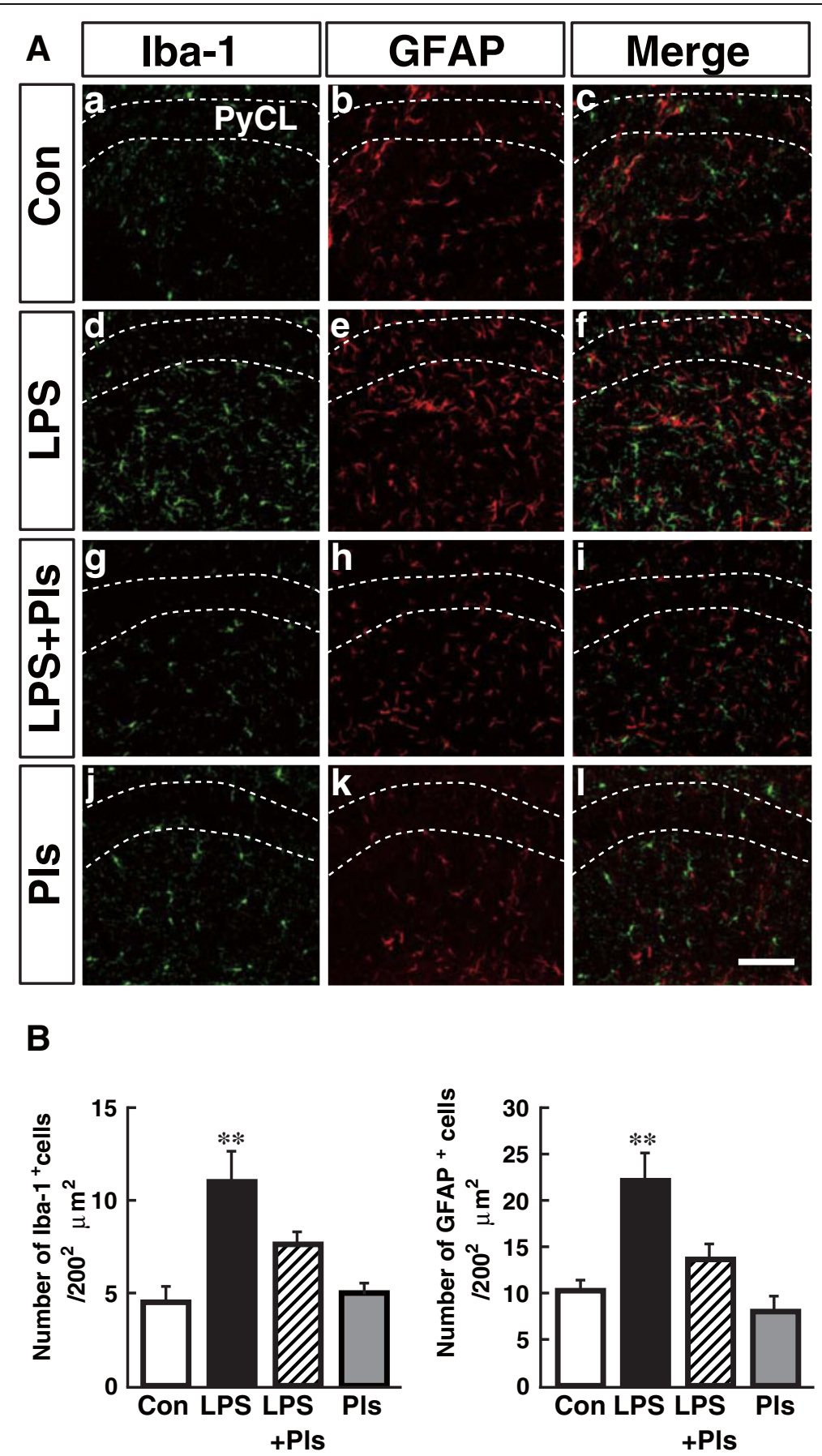

Figure 3 Activation of glial cells following LPS (i.p.) injection and suppression by Pls in the murine CA1 region of the hippocampus. A, Iba-1-positive microglia (green) and GFAP-positive astrocytes (red). The number and intensity of immunoreactivity of microglia and astrocytes increased following LPS treatment ( $\mathrm{d}$ and e) compared with that observed in the Con group ( $\mathrm{a}$ and $\mathrm{b}$ ) and was suppressed by PIs ( $\mathrm{g}$ and $\mathrm{h}$ ). They did not merge with each other (right column). PyCL: pyramidal cell layer of the hippocampus. Scale bar: $100 \mu$ m. B, A summary of LPS-induced increases in the numbers of microglia (left) and astrocytes (right) and suppression by Pls (each bar, $\mathrm{n}=8$ ). ${ }^{*}, P<0.01$. Con, control; GFAP, glial fibrillary acidic protein; i.p., intraperitoneal; LPS, lipopolysaccharide; Pls, plasmalogens.

Changes in the PI levels in the brain after LPS and PI treatment

As shown in Table 2, the levels of PlsEtn were much higher than those of PlsCho both in the PFC and the hippocampus, although more than $60 \%$ of the phospholipids were diacylgylycereophospholipids (PEtn, PCho, PS and PI). The relative levels of PlsEtn in the PFC significantly changed following LPS injection (Table 2, upper, 


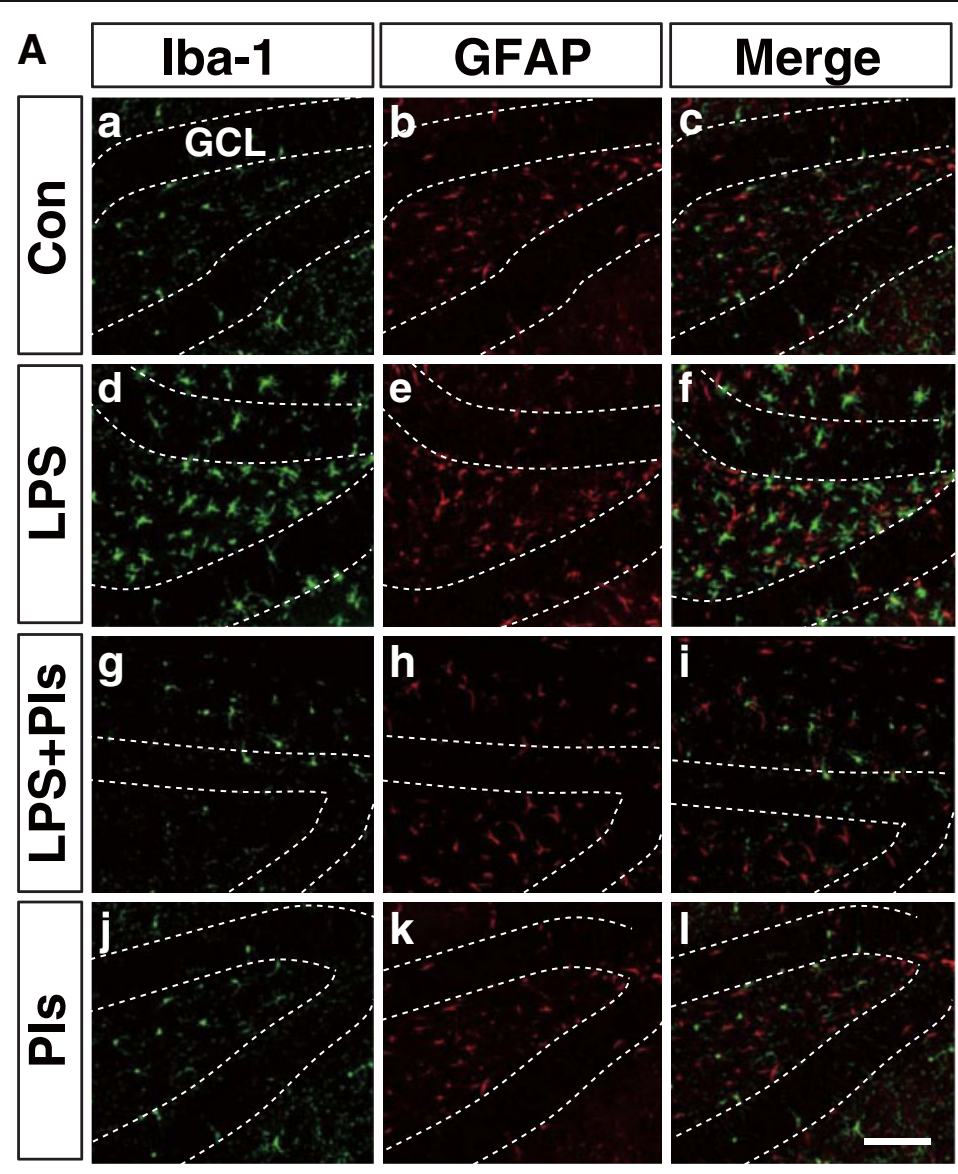

B
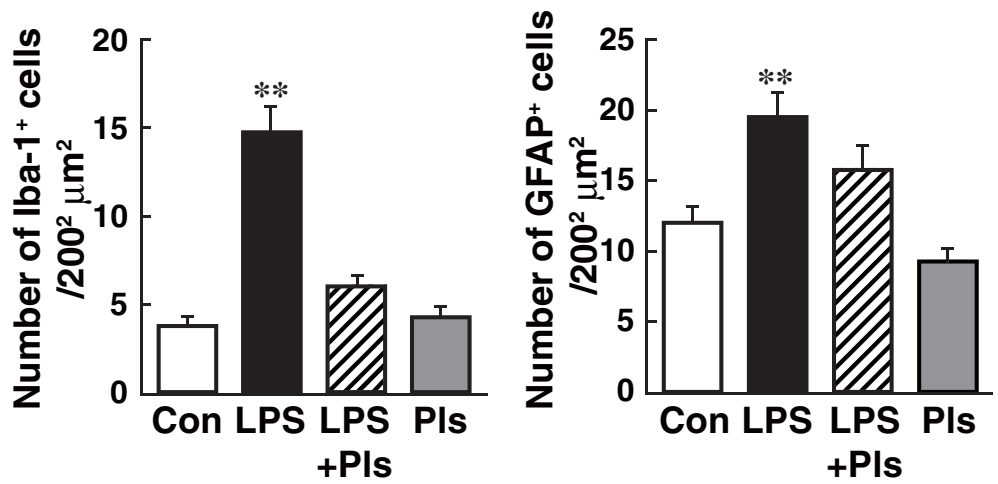

Figure 4 Activation of glial cells following LPS (i.p.) injection and suppression by Pls in the murine dentate gyrus of the hippocampus. A, Iba-1-positive microglia (green) and GFAP-positive astrocytes (red). The number and intensity of immunoreactivity of microglia and astrocytes increased following LPS treatment ( $\mathrm{d}$ and e) compared with that observed in the Con group ( $\mathrm{a}$ and $\mathrm{b}$ ) and was suppressed by Pls ( $\mathrm{g}$ and $\mathrm{h}$ ). They did not merge with each other (right column). GCL: granule cell layer. Scale bar: $100 \mu \mathrm{m}$. B, A summary of LPS-induced increases in the numbers of microglia (left) and astrocytes (right) and suppression by Pls (each bar, $n=8$ ). **, $P<0.01$. Con, control; GFAP, glial fibrillary acidic protein; i.p., intraperitoneal; LPS, lipopolysaccharide; Pls, plasmalogens.

Kruskal-Wallis test, $\left.\chi^{2}(3)=10.7, P<0.05\right)$. A multiple comparison analysis using the Steel test revealed that the amount of PlsEtn significantly decreased in the LPS group in comparison to that observed in the control group $(P<0.05)$; however, the levels in the LPS + Pls group were not different from those observed in the control group (each group: $n=5$ ). Therefore, the ratio of PlsEtn/PEtn significantly decreased following LPS 


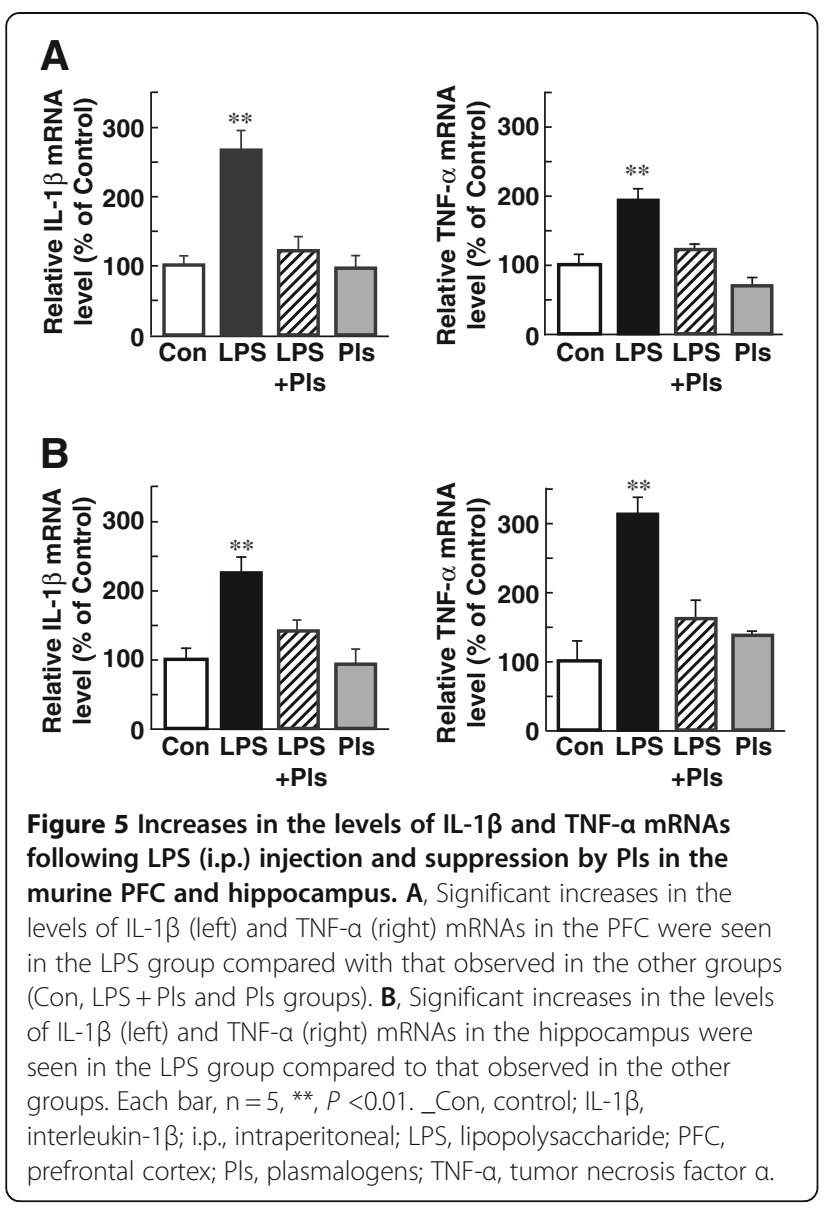

treatment $\left(\chi^{2}(3)=11.5, P<0.01\right.$ and Steel test, $\left.P<0.05\right)$ and recovered after the i.p. administration of Pls.

As shown in the lower part of Table 2, the relative levels of PlsEtn in the hippocampus were greater than those in the PFC in any group (for example, $16.40 \pm 0.59$ versus $24.18 \pm 0.64$ in the Con group). Similar to that observed in the PFC, both the relative levels of PlsEtn and the PlsEtn/PEtn ratio were significantly reduced by LPS treatment (Kruskal-Wallis test, $X^{2}(3)=11.3$ and $\chi^{2}$ (3) $=11.4, P<0.01$, and Steel test, $P<0.05$, respectively). The reduction of the PlsEtn levels in the hippocampus was also reversed by $\mathrm{Pl}$ administration. The levels of the other phospholipids did not show any significant changes following all of the treatments.

\section{Discussion}

The present study demonstrated that systemic LPSinduced activation of glial cells, cytokine expression and accumulation of $\mathrm{A} \beta$ in the PFC and hippocampus were prevented by co-administration of purified Pls in adult mice. Furthermore, the injection of LPS induced decreases in the Pl levels in the PFC and hippocampus that were also suppressed by the administration of Pls.

\section{Mechanisms of LPS-induced accumulation of $A \beta$}

It is well known that the activation of microglia and astrocytes plays an important role in neuroinflammation induced by systemic LPS by enhancing the secretion of cytokines, prostanoids, ROS/RNS and related substances. In the present study, i.p. injection of LPS for seven days induced morphological activation and increased the number of glial cells in the PFC and hippocampus (Figures 2-4). The amounts of IL-1 $\beta$ and TNF- $\alpha$ mRNAs, which are considered to be derived primarily from glial cells, also increased following LPS injection (Figure 5). Furthermore, LPS injection resulted in the intracellular accumulation of $A \beta$ proteins in both regions (Figures 6 and 7). It has been reported that i.p. injection of LPS induces deficits in spatial learning in mice $[24,25]$ that may be due to the enhancement of $A \beta$ generation in the hippocampus [1].

It is known that $\beta$-secretase is involved in amyloidogenic processing of amyloid precursor proteins at the first step, while $\gamma$-secretase yields $A \beta$ isoforms such as the more prevalent $A \beta_{40}$ and aggregation-prone $A \beta_{42}$ at the last step [26]. It has been recently shown that the activities of $\beta$ - and $\gamma$-secretase are increased in the cortex and hippocampus following systemic injection of LPS [1]. It is possible that microglia play important roles in this phenomenon since proinflammatory cytokines, as well as ROS/RNS, released from activated microglia augment $A \beta$ formation by upregulating $\beta$-secretase mRNA and enzymatic activity [5,27]. Microglia are activated further through receptors for advanced glycation end products (RAGE), which bind to $A \beta$ and induce phagocytosis of $A \beta$, thereby amplifying the generation of ROS/RNS and cytokines [26].

\section{Changes in the PI levels during neuroinflammation}

In addition to observing the activation of glial cells and $A \beta$ accumulation, we found that the Pl levels in the PFC and hippocampus decreased following LPS administration (Table 2). It is possible that the decreases in the amount of Pls during neuroinflammation are due to the anti-oxidant properties of Pls. It has been shown that the $\mathrm{Pl}$-specific vinyl ether bond at the $s n-1$ of the glycerol backbone is targeted by a variety of oxidants, including ROS/RNS [10,11,13], and oxidative stress preferentially oxidizes PlsEtn over phosphatidyl ethanolamine (PEtn) $[28,29]$, resulting in the disruption of vesicular fusion in the synaptosomes and the decrease in acetylcholine release [30]. This may at least partly explain why $\mathrm{AD}$ patients show decreases in Pl levels in the brain [14-16]. It has been suggested that abnormal membrane lipid compositions, namely decreases in the ratio of $\mathrm{Pl}$ to non-Pl ethanolamine glycerophospholipids, cause membrane instability in $\mathrm{AD}$, which may contribute to amyloidogensis by cooperatively acting with amyloid 


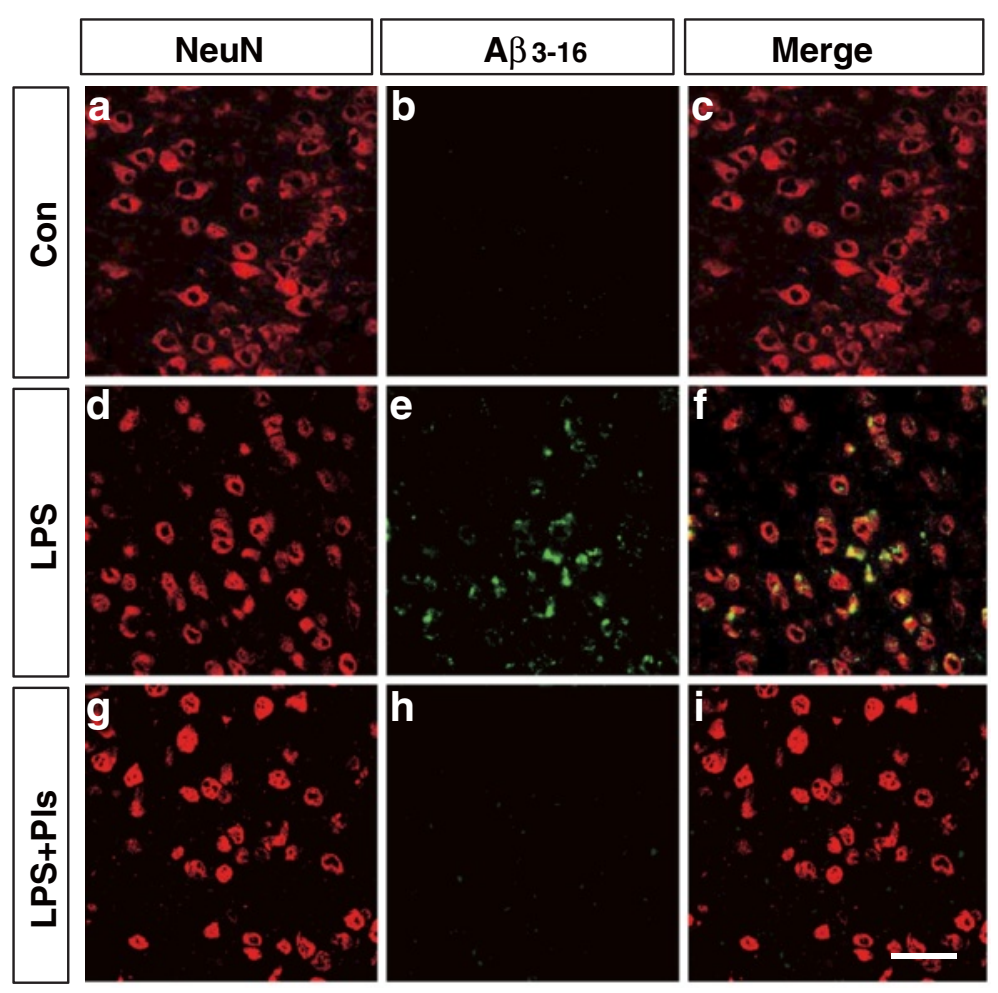

Figure 6 Accumulation of A $\beta$ proteins following LPS (i.p.) injection and suppression by Pls in the murine PFC. Neurons were stained with NeuN (red). A weak fluorescence for $A \beta_{3-16}$ immunoreactivity (green) in the Con group (b) increased following LPS treatment (e) and was completely abolished by PI administration (h). The $A \beta_{3-16}$ fluorescence merged with the NeuN immunoreactivity, indicating the intracellular localization of A $\beta$ (f). Scale bar: 50 mm. Aß, $\beta$-amyloid; Con, control; i.p., intraperitoneal; LPS, lipopolysaccharide; PFC, prefrontal cortex; PIs, plasmalogens.

cascade mechanisms [14]. Furthermore, since PlsEtn are major endogenous lipid constituents that facilitate membrane fusion of synaptic vesicles associated with neurotransmitter release [31,32], pathological and/or age-related alterations in the $\mathrm{Pl}$ levels may be attributed to neurological disorders including AD [7]. In accordance with this, it has been reported that decreases in the amount of Pls are closely correlated with the severity of dementia in humans $[18,19]$.

\section{Neuroinflammation-A $\beta$-PIs loop}

There seems to be a causes/consequences loop involving neuroinflammation that includes cytokine and ROS/RNS production, $A \beta$ accumulation and decreases in the amount of Pls. LPS-induced activation of $\beta$-secretase [1], which is predominantly localized in cholesterol-rich lipid rafts $[33,34]$, causes accumulation of $A \beta$ proteins. $A \beta-$ induced production of ROS/RNS that enhance lipid peroxidation [35,36] may decrease Pl levels, as mentioned above. In addition, increases in A $\beta$, cytokines and ROS/ RNS reduce the expression of alkyl-dihydroxyacetone phosphate-synthase, a rate-limiting enzyme for $\mathrm{Pl} d e$ novo synthesis, by inducing the dysfunction of peroxisomes, where Pls are biosynthesized, resulting in decreases in the Pl levels [37]. It has also been reported that TNF- $\alpha$ down regulates another key enzyme in $\mathrm{Pl}$ biosynthesis in peroxisomes, glycerol-3-phosphate-Oacyltransferase [38], and up regulates myeloperoxidase, which generates one of the reactive species, hypochlorous acid $(\mathrm{HOCl})$, in the brain, targeting Pls to be oxidized [39]. Finally, Pls-PLA 2 , which degrades Pls to release DHA or ARA from the $s n-2$ position of the glycerol moiety, is possibly activated by ceramide produced under inflammatory conditions, and contributes to the loss of Pls in the brain $[9,40]$.

It is well known that the generation and clearance of $\mathrm{A} \beta$ are affected by cholesterol metabolism, as evidenced by the identification of a variant gene of apolipoprotein $\mathrm{E}$, a cholesterol transporter, as a major genetic risk factor for $\mathrm{AD}[26,41,42]$. It has been shown that decreases in the amount of Pls induce a decreased rate of intracellular cholesterol transport from cell membranes to the endoplasmic reticulum, which increases the cholesterol levels in cell membranes [43]. Mankidy et al. further indicated that esterification of cholesterol, an obligate step that occurs prior to efflux from cells, is dependent upon the amount of polyunsaturated fatty acid (PUFA)containing PlsEtn present in the membrane with 


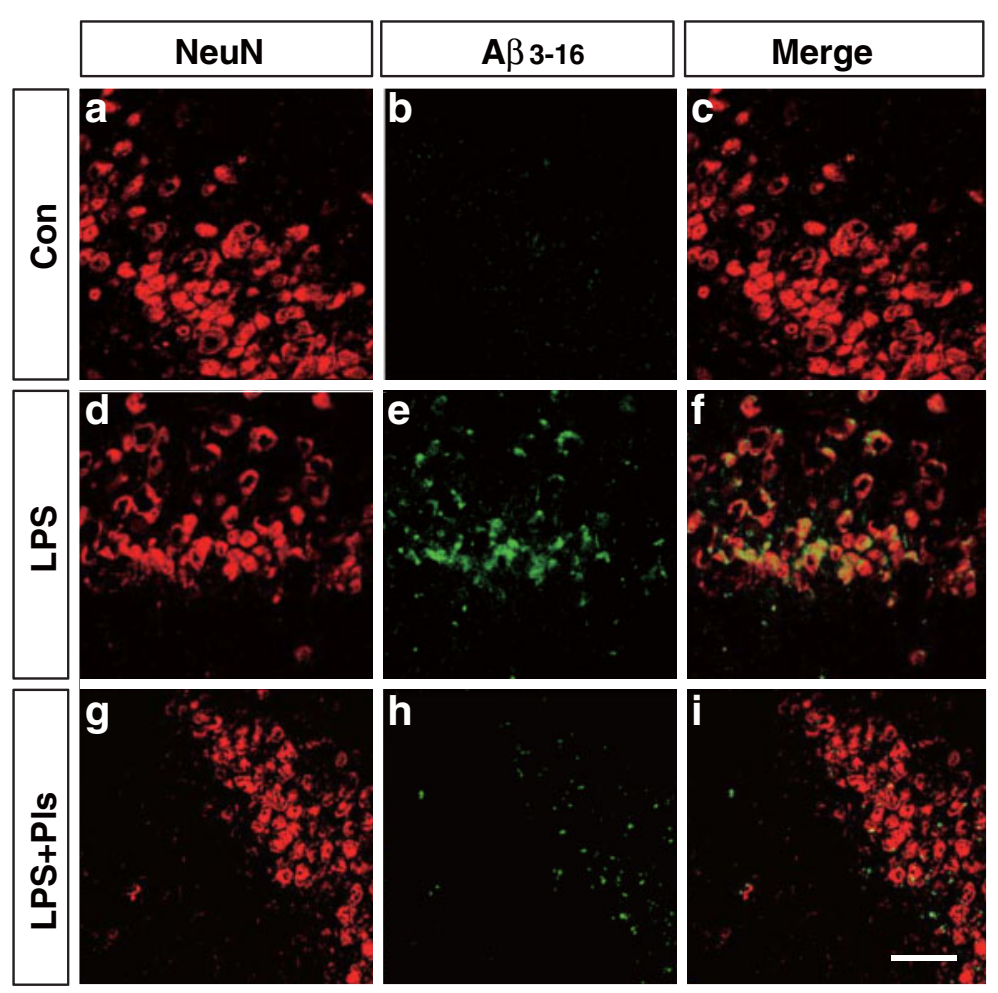

Figure 7 Accumulation of $A \beta$ proteins following LPS (i.p.) injection and suppression by Pls in the murine CA1 region of the hippocampus. Neurons were stained with NeuN (red). A weak fluorescence for $A \beta_{3-16}$ immunoreactivity (green) in the Con group (b) increased following LPS treatment (e) and was markedly attenuated by PI administration (h). The $A \beta_{3-16}$ fluorescence merged with the NeuN immunoreactivity, indicating the intracellular localization of $A \beta$ ( $f$ and i). Scale bar: $50 \mu \mathrm{m}$. A $\beta$, $\beta$-amyloid; Con, control; i.p., intraperitoneal; LPS, lipopolysaccharide; Pls, plasmalogens.

increasing levels of the membrane-bound cholesterolprocessing enzyme, sterol-O-acyltransferase-1 [44]. Increases in the cholesterol levels promote the secretion of $\mathrm{A} \beta[41,42,45]$, while depletion of cholesterol inhibits the generation of $A \beta[46,47]$. Furthermore, it has been shown that membrane Pls block cholesterol-mediated increases in $\beta$-secretase activity and directly increase the activity of $\alpha$-secretase, which is known to promote nonamyloidogenic processing of amyloid precursor proteins [48]. Therefore, a vicious circle in which LPS-induced A $\beta$ accumulation decreases the Pl levels, which leads to increased cholesterol levels, which further enhances the generation of $A \beta$ may be involved in the pathological conditions of neuroinflammation.

\section{Ameliorative effects of Pls on neuroinflammation}

In the present study, we showed that LPS-induced activation of glial cells (Figures 2-4), expression of IL-1 $\beta$ and TNF- $\alpha$ mRNAs (Figure 5), accumulation of A $\beta$ proteins (Figures 6 and 7) and decreases in the PlsEtn levels (Table 2) in the PFC and hippocampus are all prevented by co-administration of Pls. Although the precise mechanisms underlying the effects of Pls in this study are not known, supplementation with Pls could improve pathological disorders. The most important question may be whether peripheral Pls can enter into the brain. So far, there are no reports indicating that Pls directly cross the blood-brain barrier (BBB). Therefore, it is not excluded that the anti-oxidative effects of Pls are exerted outside the brain in order to suppress primary inflammation induced by peripheral LPS. However, it has been shown that the Pls levels in sera are decreased in parallel with or even at earlier times than decreases in the brain Pl levels in AD patients [18,19]. Furthermore, our results showed that LPS-induced decreases in the Pls levels in the PFC and hippocampus are corrected with peripheral administration of Pls (Table 2). Therefore, it is possible that peripheral supplementation with Pls would have effects on the CNS by changing the Pl levels in the brain.

Another question is whether the effective molecules in our experiment are PUFAs, not Pls, which Pls must carry at the $s n-2$ position. Several lines of evidence show that n-3 PUFAs, such as eicosapentaenoic acid, DHA, and its derivative, neuroprotectin D1, have anti-inflammatory and neuroprotective effects [49-52]. Furthermore, DHA has been reported to suppress the production of $\mathrm{A} \beta$ proteins through multiple mechanisms, including inhibition 
Table 2 The changes in the phospholipid levels in the PFC and hippocampus following LPS and PI injection

\begin{tabular}{lcccc}
\hline & Con & LPS & LPS + Pls & Pls \\
\hline 1) PFC & & & & \\
PIsEtn & $16.40 \pm 0.59$ & $13.41 \pm 0.73^{*}$ & $16.29 \pm 0.53$ & $17.81 \pm 0.32$ \\
PEtn & $21.92 \pm 0.63$ & $22.66 \pm 0.65$ & $22.48 \pm 0.26$ & $22.65 \pm 0.22$ \\
PlsCho & $0.20 \pm 0.03$ & $0.19 \pm 0.03$ & $0.21 \pm 0.03$ & $0.28 \pm 0.04$ \\
PCho & $44.04 \pm 1.12$ & $47.73 \pm 1.04$ & $43.73 \pm 0.97$ & $46.74 \pm 0.85$ \\
SM & $3.72 \pm 0.20$ & $3.13 \pm 0.31$ & $3.47 \pm 0.24$ & $3.31 \pm 0.15$ \\
PS & $11.88 \pm 0.27$ & $11.08 \pm 0.30$ & $12.03 \pm 0.22$ & $10.58 \pm 0.56$ \\
PI & $1.86 \pm 0.12$ & $1.80 \pm 0.07$ & $1.87 \pm 0.21$ & $1.64 \pm 0.31$ \\
PIsEtn/PEtn ratio & $0.75 \pm 0.02$ & $0.59 \pm 0.03^{*}$ & $0.73 \pm 0.03$ & $0.79 \pm 0.01$ \\
2) Hippocampus & & & & \\
PIsEtn & $24.18 \pm 0.64$ & $20.29 \pm 0.31^{*}$ & $22.88 \pm 0.45$ & $22.68 \pm 0.39$ \\
PEtn & $20.38 \pm 0.43$ & $22.07 \pm 0.62$ & $20.21 \pm 0.41$ & $20.80 \pm 0.57$ \\
PlsCho & $0.49 \pm 0.06$ & $0.42 \pm 0.04$ & $0.45 \pm 0.05$ & $0.41 \pm 0.03$ \\
PCho & $36.90 \pm 1.74$ & $39.39 \pm 0.38$ & $37.64 \pm 1.37$ & $39.90 \pm 1.04$ \\
SM & $5.24 \pm 0.67$ & $5.36 \pm 0.59$ & $5.71 \pm 0.64$ & $4.13 \pm 0.68$ \\
PS & $11.73 \pm 0.86$ & $10.94 \pm 0.25$ & $11.71 \pm 0.61$ & $10.59 \pm 0.34$ \\
PI & $1.59 \pm 0.10$ & $1.63 \pm 0.16$ & $1.72 \pm 0.06$ & $1.48 \pm 0.16$ \\
PlsEtn/PEtn ratio & $1.19 \pm 0.05$ & $0.92 \pm 0.03^{*}$ & $1.14 \pm 0.04$ & $1.09 \pm 0.05$ \\
\hline
\end{tabular}

The values are expressed as the mean $\pm \operatorname{SEM}(n=5)$ of the \% level of the phospholipids, except for the last row. ${ }^{*}, P<0.05$ compared to the Con group (Steel test for multiple comparisons). Con, control; PCho, phosphatidyl choline; PEtn, phosphatidyl ethanolamine; PFS, prefrontal cortex; LPS,

lipopolysaccharide; PI, phosphatidyl inositol; PI, plasmalogen; PIsCho, choline plasmalogen; PIsEtn, ethanolamine plasmalogen; PS, phosphatidyl serine; SEM, standard error of the mean; SM, sphingomyelin.

of $\beta$ - $/ \gamma$-secretase activities and alteration of membrane cholesterol distribution [53-55]. Since the purified Pls used in the present study contained DHA and its precursor, $\alpha$-linolenic acid, especially in PlsEtn (Table 1), it cannot be excluded that DHA derived from PlsEtn plays a significant role in the CNS effects of Pls. Indeed, it has been shown that DHA is synthesized from $\alpha$-linolenic acid and incorporated into phospholipids in the liver then transported to the brain through the peripheral circulation [56]. On the other hand, it has also been shown that lyso-type phospholipids, which contain DHA at the $s n-2$, show preferential transfer over DHA in in vitro models of the BBB [57]. Furthermore, it has been suggested that specific transport mechanisms to import Pls and their synthetic precursors exist in brain capillary epithelial cells $[58,59]$. These findings suggest that Pls containing DHA exert more effective actions in the CNS than DHA alone.

The present study suggests that co-administration of Pls suppresses systemic LPS-induced neuroinflammation in the brain. Although further studies on the mechanisms underlying these CNS effects, including the metabolism of the administered Pls and the pathways used to enter the brain, are needed, the present results indicate that Pls may possibly be used in new preventive and therapeutic strategies for treating $\mathrm{AD}$.

\section{Abbreviations}

$A \beta$ : $\beta$-amyloid proteins; AD: Alzheimer's disease; ANOVA: analysis of variance; ARA: arachidonic acid; BBB: blood-brain barrier; bp: base pair; BW: body weight; CNS: central nervous system; DG: dentate gyrus;

DHA: docosahexaenoic acid; GFAP: glial fibrillary acidic proteins; HOCl: hypochlorous acid; HPLC: high performance liquid chromatography; Iba-1: ionized calcium binding adaptor molecule-1; IFN- $\gamma$ : interferon- $\gamma$; IgG: immunoglobulin G; IL-1 $\beta$ : interleukin-1 $\beta$; i.p.: intraperitoneal; LPS: lipopolysaccharide; NSAIDs: non-steroidal anti-inflammatory drugs; PBS: phosphate buffered saline; PCho: phosphatidyl choline;

PEtn: phosphatidyl ethanolamine; PFC: prefrontal cortex; PI: phosphatidyl inositol; PIs: plasmalogens; PlsCho: choline plasmalogens;

PlsEtn: ethanolamine plasmalogens; Pls-PLA 2 : plasmalogens-selective phospholipase $\mathrm{A}_{2}$; poly I:C: polyriboinosinic:polyribocytidylic acid; PPAR-y: peroxisome proliferator-activated receptor- $\gamma$; PS: phosphatidyl serine; PUFA: polyunsaturated fatty acid; RAGE: receptors for advanced glycation end products; ROS/RNS: reactive oxygen/nitrogen species;

SM: sphingomyelin; TLR: toll-like receptor; TNF-a: tumor necrosis factor-a.

\section{Competing interests}

The authors declare that they have no competing interests.

\section{Authors' contributions}

Ml prepared the manuscript and performed the behavioral tests, immunohistochemistry and real-time PCR. TK designed the studies, performed the statistical analysis and wrote the manuscript. SM measured the levels of the brain Pls and analyzed the fatty acid composition of the Pls. $\mathrm{MN}$ assisted with manuscript preparation and discussed the data. KM and MS together prepared the purified PIs. TF designed the studies and reviewed and discussed the data. All authors read and approved the final manuscript.

\section{Acknowledgements}

We would like to thank Brian Quinn, Editor-in-Chief, Japan Medical Communication for linguistic advice on our manuscript. This work was supported by Grants-in-Aid for Scientific Research (22590225) to TK from the Japanese Ministry of Education, Culture, Sports, Science and Technology.

\section{Author details}

'Department of Integrative Physiology, Graduate School of Medical Sciences, Kyushu University, Fukuoka 812-8582, Japan. Institute of Rheological Function of food, Kasuya-gun, Fukuoka 811-2501, Japan. ${ }^{3}$ Laboratory of Pathophysiology, Graduate School of Pharmaceutical Sciences, Kyushu University, Fukuoka 812-8582, Japan. ${ }^{4}$ Central Research Institute, Marudai Food Co. Ltd, Osaka 569-8577, Japan.

Received: 18 April 2012 Accepted: 25 July 2012

Published: 13 August 2012

\section{References}

1. Lee JW, Lee YK, Yuk DY, Choi DY, Ban SB, Oh KW, Hong JT: Neuro-inflammation induced by lipopolysaccharide causes cognitive impairment through enhancement of $\beta$-amyloid generation. I Neuroinflammation 2008, 5:37.

2. Deleidi M, Hallett PJ, Koprich JB, Chung CY, Isacson O: The Toll-like receptor-3 agonist polyinosinic:polycytidylic acid triggers nigrostriatal dopaminergic degeneration. J Neurosci 2010, 30:16091-16101.

3. Okun E, Griffioen K, Barak B, Roberts NJ, Castro K, Pita MA, Cheng A, Mughal MR, Wan R, Ashery U, Mattson MP: Toll-like receptor 3 inhibits memory retention and constrains adult hippocampal neurogenesis. Proc Natl Acad Sci U S A 2010, 107:15625-15630.

4. Blasko I, Apochal A, Boeck G, Hartmann T, Grubeck-Loebenstein B, Ransmayr G: Ibuprofen decreases cytokine-induced amyloid $\beta$ production in neuronal cells. Neurobiol Dis 2001, 8:1094-1101.

5. Sastre M, Dewachter I, Landreth GE, Willson TM, Klockgether T, van Leuven F, Heneka MT: Nonsteroidal anti-inflammatory drugs and peroxisome proliferator-activated receptor- $\gamma$ agonists modulate immunostimulated processing of amyloid precursor protein through regulation of $\beta$-secretase. J Neurosci 2003, 23:9796-9804. 
6. Yan Q, Zhang J, Liu H, Babu-Khan S, Vassar R, Biere AL, Citron M, Landreth G: Anti-inflammatory drug therapy alters $\beta$-amyloid processing and deposition in an animal model of Alzheimer's disease. J Neurosci 2003 23:7504-7509.

7. Farooqui AA, Horrocks LA: Plasmalogens: workhorse lipids of membranes in normal and injured neurons and glia. Neuroscientist 2001, 7:232-245.

8. Farooqui AA, Horrocks LA: Plasmalogens, phospholipase A2, and docosahexaenoic acid turnover in brain tissue. J Mol Neurosci 2001 , 16:263-272. discussion 279-284.

9. Farooqui AA: Studies on plasmalogen-selective phospholipase A2 in brain. Mol Neurobiol 2010, 41:267-273.

10. Khaselev N, Murphy RC: Susceptibility of plasmenyl glycerophosphoethanolamine lipids containing arachidonate to oxidative degradation. Free Radic Biol Med 1999, 26:275-284

11. Engelmann B: Plasmalogens: targets for oxidants and major lipophilic antioxidants. Biochem Soc Trans 2004, 32:147-150.

12. Maeba R, Ueta N: Ethanolamine plasmalogen and cholesterol reduce the total membrane oxidizability measured by the oxygen uptake method. Biochem Biophys Res Commun 2003, 302:265-270.

13. Yavin E, Gatt S: Oxygen-dependent cleavage of the vinyl -ether linkage of plasmalogens. 2. Identification of the low-molecular-weight active component and the reaction mechanism. Eur J Biochem 1972, 25:437-446.

14. Ginsberg L, Rafique S, Xuereb JH, Rapoport SI, Gershfeld NL: Disease and anatomic specificity of ethanolamine plasmalogen deficiency in Alzheimer's disease brain. Brain Res 1995, 698:223-226.

15. Guan Z, Wang Y, Cairns NJ, Lantos PL, Dallner G, Sindelar PJ: Decrease and structural modifications of phosphatidylethanolamine plasmalogen in the brain with Alzheimer disease. J Neuropathol Exp Neurol 1999, 58:740-747.

16. Han X, Holtzman DM, McKeel DW Jr: Plasmalogen deficiency in early Alzheimer's disease subjects and in animal models: molecular characterization using electrospray ionization mass spectrometry. J Neurochem 2001, 77:1168-1180.

17. Ginsberg L, Xuereb JH, Gershfeld NL: Membrane instability, plasmalogen content, and Alzheimer's disease. J Neurochem 1998, 70:2533-2538.

18. Goodenowe DB, Cook LL, Liu J, Lu Y, Jayasinghe DA, Ahiahonu PW, Heath D, Yamazaki Y, Flax J, Krenitsky KF, Sparks DL, Lerner A, Friedland RP, Kudo T, Kamino K, Morihara T, Takeda M, Wood PL: Peripheral ethanolamine plasmalogen deficiency: a logical causative factor in Alzheimer's disease and dementia. J Lipid Res 2007, 48:2485-2498.

19. Wood PL, Mankidy R, Ritchie S, Heath D, Wood JA, Flax J, Goodenowe DB: Circulating plasmalogen levels and Alzheimer Disease Assessment ScaleCognitive scores in Alzheimer patients. J Psychiat Neurosci 2010, 35:59-62.

20. Perichon R, Moser AB, Wallace WC, Cunningham SC, Roth GS, Moser HW: Peroxisomal disease cell lines with cellular plasmalogen deficiency have impaired muscarinic cholinergic signal transduction activity and amyloid precursor protein secretion. Biochem Biophys Res Commun 1998, 248:57-61.

21. Mawatari S, Yunoki K, Sugiyama M, Fujino T: Simultaneous preparation of purified plasmalogens and sphingomyelin in human erythrocytes with phospholipase A1 from Aspergillus orizae. Biosci Biotechnol Biochem 2009, 73:2621-2625

22. Mawatari S, Okuma Y, Fujino T: Separation of intact plasmalogens and all other phospholipids by a single run of high-performance liquid chromatography. Anal Biochem 2007, 370:54-59.

23. Folch J, Lees M, Sloane Stanley GH: A simple method for the isolation and purification of total lipides from animal tissues. J Biol Chem 1957, 226:497-509.

24. Boehm GW, Sparkman NL, Martin LA, Calvert WS: Effects of intraperitoneal lipopolysaccharide on Morris maze performance in year-old and 2month-old female C57BL/6J mice. Behav Brain Res 2005, 159:145-151.

25. Shaw KN, Commins S, O'Mara SM: Lipopolysaccharide causes deficits in spatial learning in the watermaze but not in BDNF expression in the rat dentate gyrus. Behav Brain Res 2001, 124:47-54.

26. Querfurth HW, LaFerla FM: Alzheimer's disease. N Engl J Med 2010, 362:329-344.

27. Blasko I, Marx F, Steiner E, Hartmann T, Grubeck-Loebenstein B: TNFa plus IFN $\gamma$ induce the production of Alzheimer $\beta$-amyloid peptides and decrease the secretion of APPs. FASEB J 1999, 13:63-68.

28. Reiss D, Beyer K, Engelmann B: Delayed oxidative degradation of polyunsaturated diacyl phospholipids in the presence of plasmalogen phospholipids in vitro. Biochem J 1997, 323:807-814
29. Zoeller RA, Grazia TJ, LaCamera P, Park J, Gaposchkin DP, Farber HW: Increasing plasmalogen levels protects human endothelial cells during hypoxia. Am J Physiol Heart Circ Physiol 2002, 283:H671-H679.

30. Urano S, Asai Y, Makabe S, Matsuo M, Izumiyama N, Ohtsubo K, Endo T: Oxidative injury of synapse and alteration of antioxidative defense systems in rats, and its prevention by vitamin E. Eur J Biochem 1997 245:64-70.

31. Lohner K, Balgavy P, Hermetter A, Paltauf F, Laggner P: Stabilization of nonbilayer structures by the etherlipid ethanolamine plasmalogen. Biochim Biophys Acta 1991, 1061:132-140.

32. Breckenridge WC, Morgan IG, Zanetta JP, Vincendon G: Adult rat brain synaptic vesicles. II. Lipid composition. Biochim Biophys Acta 1973, 320:681-686.

33. Cordy JM, Hussain I, Dingwall C, Hooper NM, Turner AJ: Exclusively targeting $\beta$-secretase to lipid rafts by GPI-anchor addition up-regulates $\beta$-site processing of the amyloid precursor protein. Proc Natl Acad Sci US A 2003, 100:11735-11740.

34. Riddell DR, Christie G, Hussain I, Dingwall C: Compartmentalization of $\beta$-secretase (Asp2) into low-buoyant density, noncaveolar lipid rafts. Curr Biol 2001, 11:1288-1293.

35. Butterfield DA, Lauderback CM: Lipid peroxidation and protein oxidation in Alzheimer's disease brain: potential causes and consequences involving amyloid $\beta$-peptide-associated free radical oxidative stress. Free Radic Biol Med 2002, 32:1050-1060.

36. Christen Y: Oxidative stress and Alzheimer disease. Am J Clin Nutr 2000, 71:621S-629S.

37. Grimm MOW, Kuchenbecker J, Rothhaar TL, Grosgen S, Hundsdorfer B, Burg VK, Friess P, Muller U, Grimm HS, Riemenschneider M, Hartmann T: Plasmalogen synthesis is regulated via alkyl-dihydroxyacetonephosphatesynthase by amyloid precursor protein processing and is affected in Alzheimer's disease. J Neurochem 2011, 116:916-925.

38. Cimini A, Bernardo A, Cifone MG, Di Marzio L, Di Loreto S: TNFa downregulates PPAR expression in oligodendrocyte progenitor cells: implications for demyelinating diseases. Glia 2003, 41:3-14.

39. Üllen A, Fauler G, Köfeler H, Waltl S, Nusshold C, Bernhart E, Reicher H, Leis HJ, Wintersperger A, Malle E, Sattler W: Mouse brain plasmalogens are targets for hypochlorous acid-mediated modification in vitro and in vivo. Free Rad Biol Med 2010, 49:1655-1665.

40. Latorre E, Collado MP, Fernandez I, Aragones MD, Catalan RE: Signaling events mediating activation of brain ethanolamine plasmalogen hydrolysis by ceramide. Eur J Biochem 2003, 270:36-46.

41. Frears ER, Stephens DJ, Walters CE, Davies H, Austen BM: The role of cholesterol in the biosynthesis of $\beta$-amyloid. Neuroreport 1999, 10:1699-1705.

42. Puglielli L, Tanzi RE, Kovacs DM: Alzheimer's disease: the cholesterol connection. Nat Neurosci 2003, 6:345-351.

43. Munn NJ, Arnio E, Liu D, Zoeller RA, Liscum L: Deficiency in ethanolamine plasmalogen leads to altered cholesterol transport. J Lipid Res 2003, 44:182-192.

44. Mankidy R, Ahiahonu PW, Ma H, Jayasinghe D, Ritchie SA, Khan MA, SuMyat KK, Wood PL, Goodenowe DB: Membrane plasmalogen composition and cellular cholesterol regulation: a structure activity study. Lipids Health Dis 2010, 9:62.

45. Chauhan NB: Membrane dynamics, cholesterol homeostasis, and Alzheimer's disease. J Lipid Res 2003, 44:2019-2029.

46. Simons M, Keller P, De Strooper B, Beyreuther K, Dotti CG, Simons K: Cholesterol depletion inhibits the generation of $\beta$-amyloid in hippocampal neurons. Proc Natl Acad Sci U S A 1998, 95:6460-6464.

47. Kojro E, Gimpl G, Lammich S, Marz W, Fahrenholz F: Low cholesterol stimulates the nonamyloidogenic pathway by its effect on the a-secretase ADAM 10. Proc Natl Acad Sci U S A 2001, 98:5815-5820.

48. Wood PL, Khan MA, Mankidy R, Smith T, Goodenowe DB: Alzheimer's Disease Pathogenesis-Core Concepts, Shifting Paradigms and Therapeutic Targets. In Plasmalogen deficit: a new and testable hypothesis for the etiology of Alzheimer's disease. Edited by De La Monte S: InTech. 2011. http://www.intechopen.com/books/alzheimer-s-disease-pathogenesiscore-concepts-shifting-paradigms-and-therapeutic-targets/plasmalogendeficit-a-new-and-testable-hypothesis-for-the-etiology-of-alzheimer-sdisease.

49. Farooqui AA, Horrocks LA, Farooqui T: Modulation of inflammation in brain: a matter of fat. J Neurochem 2007, 101:577-599. 
50. Calon F, Lim GP, Yang F, Morihara T, Teter B, Ubeda O, Rostaing P, Triller A, Salem N Jr, Ashe KH, Frautschy SA, Cole GM: Docosahexaenoic acid protects from dendritic pathology in an Alzheimer's disease mouse model. Neuron 2004, 43:633-645.

51. Palacios-Pelaez R, Lukiw WJ, Bazan NG: Omega-3 essential fatty acids modulate initiation and progression of neurodegenerative disease. Mol Neurobiol 2010, 41:367-374.

52. Schmitz G, Ecker J: The opposing effects of $n-3$ and $n-6$ fatty acids. Prog Lipid Res 2008, 47:147-155.

53. Grimm MOW, Kuchenbecker J, Grosgen S, Burg VK, Hundsdorfer B, Rothhaar TL, Friess P, de Wilde MC, Broersen LM, Penke B, Péter M, Vígh L, Grimm HS, Hartmann T: Docosahexaenoic acid reduces amyloid beta production via multiple pleiotropic mechanisms. J Biol Chem 2011, 286:14028-14039.

54. Walsh DM, Selkoe DJ: Deciphering the molecular basis of memory failure in Alzheimer's disease. Neuron 2004, 44:181-193.

55. Oksman M, livonen H, Hogyes E, Amtul Z, Penke B, Leenders I, Broersen L, Lutjohann D, Hartmann T, Tanila H: Impact of different saturated fatty acid, polyunsaturated fatty acid and cholesterol containing diets on $\beta$-amyloid accumulation in APP/PS1 transgenic mice. Neurobiol Dis 2006, 23:563-572.

56. Scott BL, Bazan NG: Membrane docosahexaenoate is supplied to the developing brain and retina by the liver. Proc Natl Acad Sci U S A 1989 86:2903-2907.

57. Bernoud N, Fenart L, Moliere P, Dehouck MP, Lagarde M, Cecchelli R, Lecerf $\mathrm{J}$ : Preferential transfer of 2-docosahexaenoyl-1-lysophosphatidylcholine through an in vitro blood-brain barrier over unesterified docosahexaenoic acid. J Neurochem 1999, 72:338-345.

58. Wood PL, Khan MA, Smith T, Ehrmantraut G, Jin W, Cui W, Braverman NE, Goodenowe DB: In vitro and in vivo plasmalogen replacement evaluations in rhizomelic chrondrodysplasia punctata and PelizaeusMerzbacher disease using PPI-1011, an ether lipid plasmalogen precursor. Lipids Health Dis 2011, 10:182.

59. Candela P, Gosselet F, Miller F, Buee-Scherrer V, Torpier G, Cecchelli R, Fenart L: Physiological pathway for low-density lipoproteins across the blood-brain barrier: transcytosis through brain capillary endothelial cells in vitro. Endothelium 2008, 15:254-264.

doi:10.1186/1742-2094-9-197

Cite this article as: Ifuku et al:: Anti-inflammatory/anti-amyloidogenic

effects of plasmalogens in lipopolysaccharide-induced neuroinflammation in adult mice. Journal of Neuroinflammation 2012 9:197.

\section{Submit your next manuscript to BioMed Central and take full advantage of:}

- Convenient online submission

- Thorough peer review

- No space constraints or color figure charges

- Immediate publication on acceptance

- Inclusion in PubMed, CAS, Scopus and Google Scholar

- Research which is freely available for redistribution 